\title{
5-methylcytosine mediates nuclear export of mRNA
}

\author{
Cell Research (2017) 27:717-719. doi:10.1038/cr.2017.73; published online 23 May 2017
}

\section{5-methylcytosine was shown be-} fore to be an epitranscriptomic mark. Yang et al. now explored the unique topology of this mRNA modification, identified its writer and demonstrated its involvement in nuclear-cytoplasmic shuttling mediated by a specific reader.

More than one hundred modified nucleotides, in addition to the four canonical A, C, G and U letters, are found in RNA molecules, mainly in highly abundant RNA species such as rRNA and tRNA. The last decade witnessed the mapping and characterization of a growing number of mRNA-decorating modified nucleotides collectively constituting the nascent field known as epitranscriptomics [1]. Starting with the deciphering of inosine (I) and $N^{6}$-methyladenosine $\left(\mathrm{m}^{6} \mathrm{~A}\right)$ and followed by the identification of 5-methylcytosine $\left(\mathrm{m}^{5} \mathrm{C}\right)$, 5-hydroxymethylcytosine $\left(\mathrm{hm}^{5} \mathrm{C}\right)$, pseudouridine $(\psi), N^{1}$-methyadenosine $\left(\mathrm{m}^{1} \mathrm{~A}\right), 2^{\prime}-O$ methylnucleotides $(\mathrm{Nm})$ and $N^{6}-2^{\prime}-$ $O$-dimethyladenosine $\left(\mathrm{m}^{6} \mathrm{Am}\right)$, the epitranscriptome alphabet is rapidly expanding [1].

$\mathrm{m}^{5} \mathrm{C}$ is the time-honored prototypic DNA modification, a major player in gene expression control and epigenetic regulation. It turned out that RNA is also decorated by $\mathrm{m}^{5} \mathrm{C}$. rRNA marking by $\mathrm{m}^{5} \mathrm{C}$ was demonstrated in bacteria, archaea and eukaryotes whereas tRNA marking was found only in the latter two [2]. Archaeal and viral mRNA m ${ }^{5} \mathrm{C}$ decoration was clearly demonstrated, and some indications for eukaryotic mRNA marking also surfaced [2]. In recent years, based on the advance of bisulfite deep RNA sequencing and additional high throughput methodologies, more than $10000 \mathrm{~m}^{5} \mathrm{C}$ sites were identified in the human transcriptome, and were reported to be enriched in the untranslated regions (UTRs) of mRNA transcripts [3]. A prominently augmented $\mathrm{m}^{5} \mathrm{C}$ marking was reported in the vicinity of Argonaute protein binding sites, suggesting a role in gene expression regulation. $\mathrm{m}^{5} \mathrm{C}$ decoration of mRNA was found to be dynamic, with some indications for a role in protein translation. Yet, much remained to be studied regarding cellular machineries involved in regulation of $\mathrm{m}^{5} \mathrm{C}$ RNA decoration and in mediation of $\mathrm{m}^{5} \mathrm{C}$ regulated activities.

The extent of information available regarding the biological significance of the various epitranscriptomic marks differs widely. Some criteria enable us to evaluate, based on current knowledge, the relevance of each type of modification to cellular and organismal functions in the context of RNA epigenetics. These criteria include characteristic topology, evolutionary conservation, dynamic and reversible marking, identification of specific writers, readers and erasers, and documented links to biochemical and cellular outcomes. $\mathrm{m}^{6} \mathrm{~A}$ marking currently provides the gold standard for a key player in the epitranscriptomic network. This modification is non-randomly distributed along mRNA landmarks, with enhanced decoration of stop codon and the proximal 3' UTR regions as well as of long exons [4]. $\mathrm{m}^{6} \mathrm{~A}$ is dynamic in response to environmental signals and is highly conserved [4]. Both writers and erasers of $\mathrm{m}^{6} \mathrm{~A}$ are known, further alluding to the dynamic nature of this new type of epigenetic regulation [1,4]. A major key to deciphering cellular functions mediated by $\mathrm{m}^{6} \mathrm{~A}$ was the identification of specific readers, members of the YTH and the HNRNP protein families, that are recruited to the modified nucleotide embedded in a typical motif and mediate its downstream activities [4]. Much like DNA methyl-CpG-binding proteins at the time, it was the discovery of $\mathrm{m}^{6} \mathrm{~A}$-binding proteins that proved instrumental in uncovering its functions and mechanisms of action. After revealing how cells read $\mathrm{m}^{6} \mathrm{~A}$, the first molecular mechanisms soon followed. $\mathrm{m}^{6} \mathrm{~A}$ recognized by specific readers was shown to be involved in the regulation of RNA splicing, mRNA recruitment to $\mathrm{P}$ bodies and degradation, translation, 3' UTR processing, microRNA biogenesis and activity, and X-chromosome inactivation [1]. $\mathrm{m}^{6} \mathrm{~A}$ was shown to be essential for cell fate decisions in early stages of embryogenesis [5], was linked to circadian control [6], and was found to be relevant to diseases such as cancer, neurodegeneration, infertility and obesity [1].

The extensive study by Yang et al. in May issue of Cell Research significantly upgrades the standing of $\mathrm{m}^{5} \mathrm{C}$ in the epitranscriptome field [7]. The detailed unique $\mathrm{m}^{5} \mathrm{C}$ topology, as explored in this study, differs from that reported before. Enhanced $\mathrm{m}^{5} \mathrm{C}$ deposition was found not only in the neighborhood of Argonaute protein binding sites, but also 


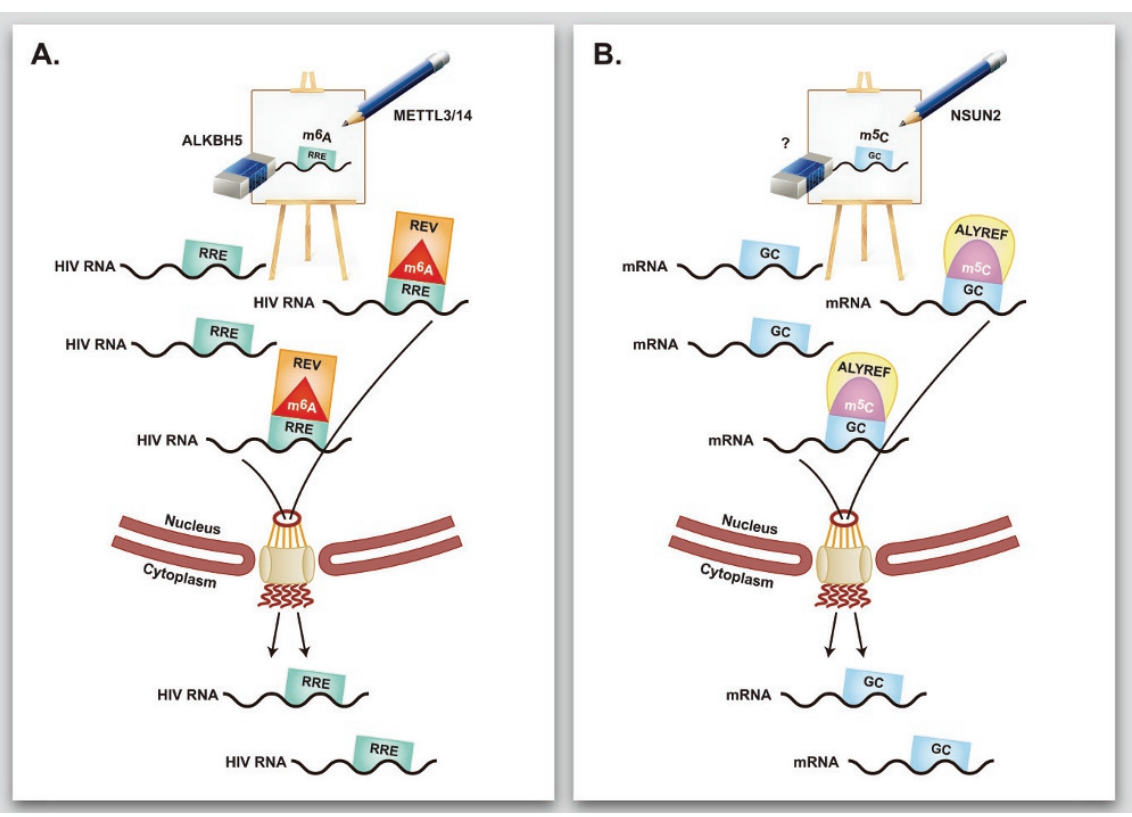

Figure 1 Epitranscriptomic marks regulate nuclear export. (A) Decoration of the HIV RNA REV Response Element (RRE) by $\mathrm{m}^{6} \mathrm{~A}$ recruits the viral REV reader protein, which accelerates nuclear export of viral transcripts [9]. $\mathrm{m}^{6} \mathrm{~A}$ writing is mediated by METTL3/14 and its erasure is mediated by ALKBH5. (B) Decoration with $\mathrm{m}^{5} \mathrm{C}$ of GC-rich regions of mRNA molecules by the NSUN2 writer enables recruitment of the ALYREF $\mathrm{m}^{5} \mathrm{C}$ reader, which mediates nuclear export.

in regions located immediately after translation initiation sites. No specific conserved methylation-directing motif was identified, yet the $\mathrm{m}^{5} \mathrm{C}$-decorated sequences are characterized by high $\mathrm{GC}$ content. The location of $\mathrm{m}^{5} \mathrm{C}$ in GC-rich sequences in the vicinity of translation start sites resembles the recently unraveled topology of $\mathrm{m}^{1} \mathrm{~A}$ [8], suggesting that $\mathrm{m}^{5} \mathrm{C}$ marking, similar to $\mathrm{m}^{1} \mathrm{~A}$ marking, may affect translation efficiency. Another major finding of the study is that NSUN2 is the main RNA methyltransferase that mediates $\mathrm{m}^{5} \mathrm{C}$ installation on mRNA. The discovery of this $\mathrm{m}^{5} \mathrm{C}$ writer opens the way to experiments exploring the role of this modification by enhancing or silencing its activity. An additional important finding is the identification of the mRNA export adaptor ALYREF as a bona fide mRNA $\mathrm{m}^{5} \mathrm{C}$ reader. The authors convincingly show that ALYREF-mediated nuclearcytoplasmic shuttling of mRNA is dependent on $\mathrm{m}^{5} \mathrm{C}$ marking by NSUN2 and precisely map K171 as the lysine residue that is essential for recruitment of the methylated transcripts. There are some indications that $\mathrm{m}^{6} \mathrm{~A}$ also affects mRNA nuclear-cytoplasmic shuttling [6], however no clear mechanistic insight is available that connects a specific endogenous cellular component of the export machinery in this case. Interestingly, the HIV-related Rev protein was shown to mediate viral RNA nuclear export, which is needed for viral replication, in an $\mathrm{m}^{6} \mathrm{~A}$-dependent manner [9]. The clear implication of ALYREF in $\mathrm{m}^{5} \mathrm{C}$-regulated nuclear export provides an excellent mechanistic illustration for modification-dependent mRNA localization mediated by an endogenous export protein (Figure 1). Having in mind the location of both $\mathrm{m}^{5} \mathrm{C}$ and $\mathrm{m}^{1} \mathrm{~A}$ in GC-rich sequences in the vicinity of translation start sites, it is tempting to explore the possibility that $\mathrm{m}^{1} \mathrm{~A}$ decoration may also affect transcript export.

The precise localization of $\mathrm{m}^{5} \mathrm{C}$ marks to a unique region brings to mind the preferred targeting of $\mathrm{m}^{1} \mathrm{~A}$ and $\mathrm{m}^{6} \mathrm{~A}$ around the start and the end of coding regions, respectively. Recent studies indicate that $\mathrm{m}^{1} \mathrm{~A}$ is located just upstream of the first exonic junction [8] whereas $\mathrm{m}^{6} \mathrm{~A}$ is found immediately downstream of the last exonic junction [10], suggesting that components of the exonic junction complex (EJC) are involved in the exact positioning of these modifications. It can be speculated that the EJC is also involved in the precise deposition of $\mathrm{m}^{5} \mathrm{C}$ in the vicinity of the translation initiation site. The assembly of nuclear export-competent messenger ribonucleoprotein complexes comprises the recruitment of export-facilitating factors to the mature mRNA. It was shown lately that a core set of export proteins containing UAP56, DDX and importantly, ALYREF, nucleate and associate with spliced transcripts in an EJC- and cap-dependent manner [11]. Further studies are needed to explore the hypothesis that EJC and ALYREF play a major role in both $\mathrm{m}^{5} \mathrm{C}$ deposition and nuclear-cytoplasmic shuttling. Additional immediate questions that are raised by this study include the role of $\mathrm{m}^{5} \mathrm{C}$ in gene expression control in general and translation in particular, a possible interaction or overlap with other modified nucleotides such as $\mathrm{m}^{1} \mathrm{~A}$ and $\mathrm{m}^{6} \mathrm{~A}$ in a kind of "epitranscriptomic code", whether there is a specific eraser that can demethylate $\mathrm{m}^{5} \mathrm{C}$ (TET protein?) and what the consequences of removal of this mark are.

The data obtained by Yang et al. and previous researchers concerning the unique telltale topology of $\mathrm{m}^{5} \mathrm{C}$, its evolutionary conservation, dynamic nature and tissue specificity as well as the identification of specific writer and reader proteins and the unequivocal mechanistic role in nuclear export, now turn $\mathrm{m}^{5} \mathrm{C}$ into a very respected citizen of the epitranscriptome world, similar to the well-established position of $\mathrm{m}^{6} \mathrm{~A}$. The findings of this paper will enable to study the role of $\mathrm{m}^{5} \mathrm{C}$ in physiological 
and pathological states. Similar to the translation of DNA and histone epigenetics into established therapies, the clarification of the players and mechanisms involved in $\mathrm{m}^{5} \mathrm{C}$ decoration and reading may open the way for novel future therapeutic interventions.

\section{Dan Dominissini ${ }^{1,2}$, Gideon Rechavi ${ }^{1,2}$}

${ }^{I}$ Cancer Research Center and the Wohl Institute for Translational Medicine, Chaim Sheba Medical Center, Tel Hashomer 52621, Israel;
${ }^{2}$ Sackler School of Medicine, Tel Aviv University, Tel Aviv 69978, Israel

Correspondence: Gideon Rechavi

E-mail: gidi.rechavi@sheba.health.gov.il

\section{References}

1 Zhao BS, Roundtree IA, He C. Nat Rev Mol Cell Biol 2017; 18:31-42.

2 Hoernes TP, Erlacher MD. Wiley Interdiscip Rev RNA 2017; 8. doi:10.1002/wrna.1375.

3 Squires JE, Patel HR, Nousch M, et al. Nucleic Acids Res 2012; 40:5023-5033.

4 Dominissini D, Moshitch-Moshkovitz S, Schwartz S, et al. Nature 2012; 485:201206.

5 Geula S, Moshitch-Moshkovitz S, Dominis- sini D, et al. Science 2015; 347:1002-1006.

6 Fustin JM, Doi M, Yamaguchi Y, et al. Cell 2013; 155:793-806.

7 Yang X, Yang Y, Sun BF, et al. Cell Res 2017; 27:606-625.

8 Dominissini D, Nachtergaele S, MoshitchMoshkovitz S, et al. Nature 2016; 530:441446.

9 Lichinchi G, Gao S, Saletore Y, et al. Nat Microbiol 2016; 1:16011.

$10 \mathrm{Ke} \mathrm{S}$, Alemu EA, Mertens C, et al. Genes Dev 2015; 29:2037-2053.

11 Gromadzka AM, Steckelberg AL, Singh KK, et al. Nucleic Acids Res 2016; 44:23482361. 